Editorial

\title{
Calidad del agua en sistemas fluviales y legislación ambiental, conduciendo en contravia
}

Uno de los elementos más importantes en la mayoría de los ecosistemas es la biota (Álvarez, Benítez, Velásquez y Cogollo, 2013), la cual abarca desde los microorganismos (como las bacterias), hasta los organismos de gran tamaño e impacto en la tierra (como los humanos). Las nuevas definiciones de los conceptos de "ecosistemas" incluyen al hombre, debido al importante papel que ha jugado en las últimas décadas (O'Neill, 2001). Estos impactos incluyen desde alteraciones a los ecosistemas naturales, pasando por la creación de ecosistemas artificiales, hasta la eliminación de ecosistemas naturales (OMS, 2006). Uno de los recursos naturales que más se ha visto afectado, son los recursos hídricos marinos (Rangel-Buitrago y Posada-Posada, 2013) y continentales (Rúa-García, 2015). Estos recursos, poseen una gran importancia para el mantenimiento de todos los ecosistemas en el planeta tierra, ya que están vinculados al ciclo hidrológico de manera directa o indirecta (Wetzel, 2001).

Históricamente, se han desarrollado normas o leyes con el propósito de usar adecuadamente los recursos hídricos, de acuerdo con sus diferentes usos: agrícola, pecuario, industrial, doméstico, entre otros. Sin embargo, las normas que han creado los legisladores van "en contravía" con lo que muchos ecologistas consideran como uso razonable de los recursos hídricos. Por ejemplo, en Colombia casi todos los usuarios de los servicios de agua potable del sector residencial pagamos un impuesto por "contaminar", denominado tasa retributiva. No obstante, la tasa retributiva que pagan los sectores agrícolas, agroindustriales e industriales son calculados (parcialmente) a partir de 
auto-declaraciones, que provienen de los resultados de los análisis de la calidad fisicoquímica y microbiológica del agua que vierten, producto de sus procesos. De tal manera que la autoridad ambiental no tiene un control directo sobre la calidad de las aguas que estas industrias vierten sobre fuentes hídricas como ríos (Cárdenas y Mair, 2014; Fontalvo y Tamaris-Turizo, 2018), los lagos (Pulido-López y Pinilla-A, 2017) o el mar (Vivas-Aguas y Navarrete, 2014).

Los impactos negativos que se han generado sobre la calidad de las aguas de sistemas fluviales, deben convertirse en un norte para realizar mejoras en la legislación colombiana con el propósito de

- i) crear métodos que permitan verificar la calidad de las aguas previo al proceso de vertimiento a los cauces naturales,

- ii) propiciar escenarios para que el sector industrial realice o innove tratamientos más efectivos sobre las aguas que provienen de sus diferentes procesos.

Estas dos iniciativas podrían llevar a que la calidad de las aguas de los sistemas fluviales y la legislación ambiental colombiana dejen de conducir en contravía.

\section{REFERENCIAS BIBLIOGRÁFICAS}

Álvarez, E., Benítez, D., Velásquez, C. \& Cogollo, A. (2013). Densidad básica del fuste de árboles del bosque seco en la costa Caribe de Colombia. Intropica, 8, 17-28.

Cárdenas, M. y Mair, J. (2014). Caracterización de macroinvertebrados bentónicos de dos ramales estuarios afectados por la actividad industrial, Estero Salado-Ecuador. Intropica, 118-128.

Fontalvo Julio F. A. y Tamaris-Turizo C.E. (2018). Calidad del agua de la parte baja del río Córdoba (Magdalena, Colombia), usando el ICA-NSF. Intropica 13(2): DOI: http:// dx.doi.org/ 10.21676/23897864.2505.

OMS (Organización Mundial de la Salud, US). (2006). Agua, saneamiento y salud: Enfermedades relacionadas con el agua_URL:_http://ho.int/wáter_saniation_health/ diseases/diseasefac/es/index.html. Consultado: 12 de diciembre de 2010

O'Neill, R. V. (2001). Is It Time to Bury the Ecosystem Concept? (with Full Military Honors, of Course!). Ecology, 82(12), 3275-3284.

Pulido-López, P. C., y Pinilla-Agudelo, G. A. (2017). Evaluación del estado trófico de El Salitre, último humedal urbano de referencia en Bogotá. Revista de la Academia Colombiana de Ciencias Exactas, Físicas y Naturales, 41(158), 41-50.

Rangel-Buitrago, N. G., Posada-Posada, B. 0. (2013). Determinación de la vulnerabilidad y el riesgo costero mediante la aplicación de herramientas SIG y métodos multicriterio en la línea de costa. Intropica, 8. 29-42.

Rúa-García, G. (2015). Macroinvertebrados acuáticos asociados a raíces de Eichhornia crassipes (mart) solms, en la ciénaga de Zapayán, Magdalena-Colombia. Intropica, 10. 52-59. 
Vivas-Aguas, L. J. y Navarrete Ramírez, S. M. (2014). Protocolo Indicador Calidad del Agua (ICAMpff). Indicadores de monitoreo biológico del Subsistema de Áreas Marinas Protegidas (SAMP). Santa Marta: INVEMAR, GEF y PNUD. Recuperado de: http://www. invemar. org. co/documents/10182/14479/04+ProtocoloIndicadorCalidaddeAguadigital.pdf/c16bd915-0b24-446b-9fe0-dbbc239111dd.

Wetzel, R. G. (2001). Limnology: lake and river ecosystems. Gulf professional publishing.

\section{CÉSAR E. TAMARIS-TURIZO'}

Universidad del Magdalena

Grupo de Investigación en Biodiversidad y Ecología Aplicada

1 Doctor en ciencias. Universidad del Magdalena.

cesartamaris@yahoo.es - Orcid ID: 0000-0001-8625-4981 